\title{
Research Paper: Evaluation the Emergency Response Program of Emergency Operations Command Center of the Alborz University of Medical Sciences in Response to Kermanshah Earthquake in November 2017
}

\author{
Farzaneh Ahmadzadeh $^{1^{*}}$ (D), Neda Mohammadi² (D, Mehrdad Babaei ${ }^{2}$ (D)
}

1. Department of Natural Disaster Engineering Management, Faculty of Environment, University of Tehran, Tehran, Iran.

2. Center for Medical Accidents and Emergencies, Alborz University of Medical Sciences, Alborz, Iran.

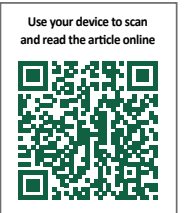

Cittion: Ahmadzadeh F, Mohammadi N, Babaei M. Evaluation the Emergency Response Program of Emergency Operations Command Center of the Alborz University of Medical Sciences in Response to Kermanshah Earthquake in November 2017. Health in Emergencies and Disasters Quarterly. 2019; 4(3):135-146. http://dx.doi.org/10.32598/hdq.4.3.135

: http://dx.doi.org/10.32598/hdq.4.3.135

\section{(1) (3)}

Article info:

Received: 10 Jul 2018

Accepted: 15 Jan 2019

Available Online: 01 Apr 2019

Keywords:

Health in emergencies, Disaster management

\begin{abstract}
Background: Among the various components of disaster management during unexpected accidents, health care systems, especially hospitals, play the most important role in providing primary care services in the initial phase of the disaster. Health services in natural and humanmade disasters are the main cause of human survival. Accidents and disasters always have a significant impact on the safety, general health, and welfare of the affected population.
\end{abstract}

Materials and Methods: In this paper, by collecting relevant data and their analyses in SPSS, we reviewed the response of the headquarters of the operation command of Alborz University of Medical Sciences to the Kermanshah earthquake in November 2017.

Results: According to the obtained results, 25-27 years old and 80 years old groups had the highest number of casualties to receive relief services. Based on the results of the analysis in SPSS, the number of injured men who received health care services was higher than women (38 men vs. 37 women). Madani Hospital admitted the highest number of victims by accepting 54 (72\%) injured people. Based on our analysis, multiple trauma had the highest prevalence $(24 \%)$ among injured people, then trauma to the foot $(9 \%)$, followed by the trauma of the lower back and hand fractures $(6.8 \%)$. Of the total 75 injured people transferred to the hospital, $39(52 \%)$ underwent the operation. One case was sent to a hospital in Tehran Province, and 7 (9\%) casualties were settled temporarily. There was a case of amputation. One patient was re-hospitalized. Finally, $4(5 \%)$ of the injured people left the hospital.

Conclusion: Regarding the services provided, it can be acknowledged that the headquarters of the Crisis Operation of the Alborz University of Medical Sciences (in spite of its new establishment) had an excellent performance regarding the type and amount of the services provided to the injured people in the field of risk management of accidents/disasters in Kermanshah earthquake in November 2017. Some of the positive and essential measures of the headquarters of crisis operation command were planning operations; triage at the airport; transfer of the injured people; coordination with the hospitals; declaration of yellow status to all medical centers; use of the full capacities of the Medical Sciences University; assignment of beds and the issue of surge capacity of health centers; communication with organizations, centers, and hospitals affiliated to Alborz University of Medical Sciences.

\footnotetext{
* Corresponding Author:

Farzaneh Ahmadzadeh, MSC.

Address: Department of Natural Disaster Engineering Management, Faculty of Environment, University of Tehran, Tehran, Iran

E-mail:farzan_yad23@yahoo.com
} 


\section{Introduction}

he evolution of human life on the earth with a history of a lot of accidents and di$\mathbf{T}$ sasters indicate that the occurrence of most disasters is still inevitable and by making changes and manipulating the environment, population, etc., societies are still growingly exposed to disasters. People always suffer and scare of events and disasters that result in injuries and deaths.

Today, disasters have created greater concerns for humans than before. The odds of unexpected accidents, which many people may be exposed to them, has increased. In other words, people are more likely to live in high-risk situations. Investigating the trend of accidents and disasters occurrence in recent years reveals that the increased incidence of major accidents is unfortunately associated with substantial financial and human losses.

According to the definition, accidents and disasters are severe geographical dislocations or high-intensity emergencies that result in consequences like death, financial loses, injuries, and diseases. The conventional methods and available resources cannot adequately control them; therefore, they need external aids [1].

According to the 2008 World Health Organization's (WHO) report, the impact of disasters on the global community has been enormous. On average, around 500 natural events are registered around the world per year. Such incidents have affected 80 million people, caused 74000 injuries, killed 50000 people, and moved 5 million people away from their residence [2].

The motto of WHO in 2009 was "Health in Disasters." WHO has obliged all its member countries to follow this motto and embark on the planning, management, coordination, training, and other necessary measures with a strong emphasis on the people's support, capacity building, and local management. Thus, in the event of accidents and disasters, these centers perform their duties in the best way, and besides saving the health of survivors, they can provide short- or long-term services to the survivors [2].

Discussing the management of natural disasters in Iran is evident and necessary. Indeed, among the various components of disaster management in the health and unexpected events sector, the health and treatment system, especially hospitals, play the most crucial role as the central unit for providing services in the initial phase.
Health services in natural disasters are the main cause of human survival. Accidents and disasters always have significant impacts on the safety, general health, and welfare of the affected population.

In the past years, it has been assumed that the performance of healthcare services is only limited to the post-incident period. However, there were many inconsistencies among the governmental and non-governmental organizations involved in health services in the post-incident phase, so pre-disaster preparedness was introduced in the health field to provide better healthcare services $[3,4]$.

\section{Literature review}

In the last decade, approximately one billion people in the world (about one-sixth of the world's population) have been directly and indirectly involved in disasters. More than $90 \%$ of deaths in developing and less-developed countries are due to accidents and disasters. Iran is a developing country in Asia that is prone to various natural and human-made disasters and is known as one of the most vulnerable countries in the world.

Accidents and disasters are defined as events that cause a disturbance in routine social activities, impose damages more than the capacity of the affected area, and create financial and human losses. Effective management of these destructive and harmful events depends on the ability to predict the complications and disasters caused by the incidents and to be prepared for effective responses to such problems $[4,5]$.

The Sarpol-e Zahab earthquake with the magnitude of 7.3 occurred near Ezgeleh City, Kermanshah Province, northwest of Iran at 23:18 local time on November 12, 2017. This earthquake caused the destruction of large parts of Sarpol-e Zahab City and many cities and villages in Kermanshah Province. There were reports that the quake was so powerful that it was felt as far away as hundreds of kilometers (even in Tehran, the capital city).

At least eight cities (Qasr-e-Shirin, Ezgeleh, Salas Babajani, Gilan-e-Gharb, Sarpol-e Zahab, Dalahoo, West Islamabad, and Javanrood) and 1933 villages were damaged. According to statistics provided by the Iran's Forensics Organization, more than 179 people died, and thousands were injured up to December 09, 2016. Of this number, Sarpol-e Zahab had the highest number of deaths (118 deaths), followed by Salas Babajani (13 deaths), Dalahoo (19 deaths), Qasr Shirin (16 deaths), West Islamabad (1 death), and Kermanshah (1 death). Despite the limited number of casualties in this earth- 
quake, compared to the earthquakes of the last three decades in Iran (e.g. Manjil-Rudbar in 1989 and Bam in 2002).

An accurate statistics on the extent of earthquake damages and their extension in different cities and villages is not available. Moreover, various sources reported different statistics at different times after the earthquake, so a precise assessment of the accuracy of these statistics is impossible.

Several national and international studies have been conducted on health issues to examine the measures and coordination of the services and health organizations of the crisis command center. For example, Leslie D. Lutz et al. explored the extent of using the Incident Command System (ICS) on the performance of the Texas Emergency Operation Centers (EOCs) during the Rita Storm. EOCs staff was assessed through a questionnaire that included evacuation, transfer, demographic variables, physical environment, ICS experience, ICS implementation, and so on.

The obtained results indicated that the task of each ICS division was significantly different from one EOC to another. In addition, the experiment and implementation of ICS were not significantly related with the environment team. Finally, it seemed that the relevant emergency organizations experienced more ICS problems, compared to the emergency mission organizations (e.g. fire station and police department) [6].

Michael Ryan et al. investigated the program and argued that programming and planning is a deliberate process that often calls for the coordinated efforts of multiple people from different disciplines. During the activation of the EOC, planning performance is critical to the success of the operation field and the overall awareness of the situation; scheduling is conducted in an exact time frame, often with limited information. However, devising a plan at such limited time is essential, and we must be assured the program will be employed more precise than ever possible [7].

Laura G. Militello et al. discussed the challenges for coordination at the EOC. At the regional level, the EOC is composed of representatives of a wide range of organizations, including local government, fire station, police department, hospital, as well as the logistics and representatives of the Red Cross agencies.

These specialized teams join together to initially help prepare and supply resources in the catastrophe, transport coordination of casualties and their tracking, and establishing emergency shelters. To observe the performance of the teams, some simulations were conducted, and the results were identified in two exercises. Finally, with regard to the outcomes, they provided recommendations for better coordination of crisis management [8].

Thomas Magnon et al. stated that since September 11, 2001, many public health organizations re-examined their capabilities and institutional methods to manage incidents with human losses involving Weapons of Mass Destruction (WMD). Before 2001, public health planning and other sectors had focused on natural disasters such as earthquakes, storms, tornadoes, and chemical agents' contamination. Attacks with WMDs were among the growing concerns. Although the nature of natural events is different from human-made events, the management and coordination of response activities follow the same incident command system.

An essential lesson in responding to September 11, 2001, New York City attacks was understanding the value of disaster management planning, performing practices, and the establishment of relationships among different response agencies. Although the New York Emergency Operations Center was destroyed at 7 World Trade Centers in the attack; the medical community was able to effectively respond to mass deaths as well as more common needs of the incident.

This matter is only possible by the development and planning of inter-organizational relations and coordination before events' occurrence [9]. In their qualitative study, Borzoui et al. stated that the importance of managing the urban crisis is because Iran is a country that is always exposed to natural disasters such as earthquakes, floods, and so on. Preventive measures to reduce casualties and financial losses from accidents and disasters have always been the concern of the authorities.

In this regard, the prediction and establishment of facilities mitigate physical and psychological harm and accident-induced mortalities that are the essential goals of crisis management. Although crisis management comprises an integrated set of government agencies and public institutions, urban management (municipality) has a leading role in crisis management. Municipalities, as public institutions, have a central responsibility in crisis management and must be the coordinator of other organizations and agents involved in crisis management.

By organizing and developing coherent programs and implementing them in the city, a dynamic crisis management system can be set up by forming a headquarters for 
operational guidance to reduce the extent of the crisis during and after the disaster. Contrary to the notion of managing a crisis, the headquarters of operational guidance will not be commanding or operating in crisis. It will instead support crisis management as well as the incident command system. It is, in fact, responsible for taking the strategic crisis decisions, while the lower levels make the operational decisions [10].

Kankeh et al. argued that the effective management of health in disasters depends on predicting and identifying problems caused by disasters and considering facilities at the right time and place. Although Iran is a disasterprone country and among the most prone countries to natural events in the world, the studies done on rendering health services in disasters show a lack of coordination in the provision and delivery of health services.

It is vital to explore disaster management services. In the current work, which is part of a more extensive study, we attempted to examine the factors affecting healthcare management at the time of disasters, based on the experiences of disaster health service providers [11].

Numerous studies have investigated the preparedness of medical centers in times of accidents. For example, a study was conducted in hospitals affiliated to Tehran School of Medicine to investigate accidents and disasters management in 2004. The results revealed that $62 \%$ of the hospitals did not have a disaster committee, and 63\% of the hospitals failed to provide any training courses in disasters management for their managers and staff.

Also, $85 \%$ of the hospital ward managers had not participated in any educational program $[2,4]$. There was no study on the management of crisis command headquarters in medical science universities and the measures taken in the pre-hospital emergency department and the control of accidents.

Introduction of Alborz University of Medical Sciences Crisis Management Command Headquarter

In 2010, the head of the center for the management of emergencies and accidents in the country ordered the establishment of the crisis management center to all medical universities. In September 2011, the Alborz Provincial Emergency Operations Command (EOC) in Alborz Province medical and emergency management center announced its official activities in a letter through an EOC's exclusive number to the university, governorate, hospitals, and all related organizations with the following objectives: 1 . Intra- and inter-unit organization and coordination in response to the disasters; 2. Observing the daily performance of the units of the center for the management of accidents and medical emergencies; 3. Establishing the necessary system and tools for prompt alerts, guidance, coordination, and strategic crisis operations.

Description of the duties of the headquarters of operational guidance: 1 . Intra- and inter-unit organization and coordination at the time of crisis; 2 . The most critical decision-making authority and leadership in crisis condition; 3. Coordinator of the pre-hospital emergency and hospital system; 4. Creating a statistical database of special events on a daily and monthly basis and comparing those with the statistical reports of police, forensic centers, and so on; 5 . Conversion of the above headquarters to the university headquarters in the face of severe accidents and disasters and conducting the crisis operations; 6. Evaluating and monitoring the performance of emergency statistics section; 7. Conducting a 24-hour activity to coordinate, receive, and record information; 8 . Tracking and receiving the reports of special and unexpected incidents from relevant authorities; 9. Informing and announcing standby to emergency centers and other relief, health, and medical centers at the time of events and disasters to meet the health and medical needs of the injured and sick people.

The performance of Alborz University of Medical Sciences Crisis Operation Command Headquarters:

1. Preparing special events statistics every month; 2. Registering and notifying special incidents reportable to the authorities and the governorate; 3. 24-hour response to an average of 100 phone calls; 4 . Concluding lessons learned from high casualty events; 5 . Providing daily reports to the center's management.

The number of staff at Alborz Medical University Operations Command Headquarters: Six elite experts are working at the Crisis Headquarters of the Alborz University of Medical Sciences in 24-hour shifts.

\section{Materials and Methods}

This research is a qualitative study in which the exact definition of the target groups and the method of implementing the services and guidance, and finally, the analysis and conclusion are described. The present study investigated the injured individuals in the Kermanshah earthquake transferred to the Alborz Province, Iran, and the services provided to them at the Headquarters of the 
operational guidance of the Alborz University of Medical Sciences in November and December 2017.

In this paper, we reviewed the services provided by the Headquarters of the Crisis Operations of the Alborz University of Medical Sciences to the earthquake injured. Then, we used the statistical data collected based on the measures and services provided and their analyses in SPSS.

Description of the services provided by the Headquarters of the Crisis Management of the Alborz University of Medical Sciences. After the earthquake in Kermanshah Province (Ezgele City as the center of the quake), the headquarters of the Crisis Operation of the Alborz University of Medical Sciences was activated and did the following measures in two brosad categories based on the response plan in the crisis:

\section{Calling and organizing with relevant organizations}

1. Activating the ICS of the University Accident and Emergency Medical Center; 2. Holding intra-unit meetings with the presence of the director, the pre-hospital emergency department manager, and the crisis management team of the center for the accident and emergency management of the province regarding the planning of the dispatching of relief teams for the transmission of earthquake-injured casualties from the western regions of the country; 3. Activating EOC of Alborz University of Medical Sciences; 4. Announcing the level of yellow status to the health centers of the province according to the Ministry of Health announcement; 5. Consulting on the availability of vacant beds and admission capacity of private and public hospitals in Alborz Province, in coordination with on-duty supervisors; 6 . Alerting the standby condition and the activation of mental health teams of the health department deputy; 7. Ordering to activate the Hospital Incident Command System (HICS) at Shahid Madani Health Center, Imam Ali complex and Alborz Hospital, and to implement "the response plan in the crisis" of these hospitals; 8 . Surging therapeutic capacity for admitting the injured people at Shahid Madani Hospital, Imam Ali Hospital, and Alborz Hospital based on hospital capacity surge plan to provide better services; 9. Calling up and providing the medical centers with a database of volunteer personnel to send to the accidentstricken center and providing a list of volunteers and management and planning to transfer the elite group to Kermanshah Province.

\section{Establishing relief teams and equipment}

1. Preparing and sending the operational teams of the Accidents and Medical Emergencies of Alborz Province, including 40 operational experts, 15 ambulances, and 2 ambulance buses for sending to Mehrabad airport and transferring the injured people; 2. Alerting the Alborz airbase relief to cover the possible transfer of the injured to Alborz Province hospitals; 3. Dispatching the expedition team of the Alborz Accident and Medical Emergencies Management team at Mehrabad airport, Tehran, after coordination with the EOC of the Ministry of Health, for triage and transfer of the injured from Kermanshah Province; 4. Establishing the Incident Command Post (ICP) in the ambulance bus at Mehrabad airport after the presence of the expedition team, the University's treatment deputy (field commander and airport triage officer), the director of the center for the accidents and medical emergency management (planning officer), pre-hospital emergency in charge (commander of rapid response and transfer teams) and the authority in charge, for providing support and logistics and EOC experts; 5. Initiating triage operation after the landing of the airplane carrying the injured at Mehrabad airport by the dispatched team from the Alborz University of Medical Sciences under the management of the deputy of treatment of Alborz University of Medical Sciences, Dr. Vaezi, and Dr. Khadem Al-Husseini; 6. Coordinating with the management of Tehran Emergency Operations team at Mehrabad airport to distribute the injured in Alborz Province; 7. According to the coordination of the Crisis Operation Management Center of Alborz University of Medical Sciences, the transfer and distribution of the injured people were done based on the determined triage and to the designated treatment centers as follows; 8. The transfer of the first group of the injured, including 35 injured people in earthquake from the west of Iran by two ambulance buses and 14 ambulances to Shahid Madani, Imam Ali, and Alborz hospitals; 9. Starting the second phase of the operations and re-dispatching two ambulance buses and 7 ambulances to the Mehrabad airport to transfer 30 other injured; 10 . Transferring 30 injured people by the operational personnel of the Alborz Medical Accident and Medical Emergency Management Center to Shahid Madani, Imam Ali, and Alborz hospitals; 11. Attending of the Deputy of Medical Treatment of Alborz University of Medical Sciences and the respected chief of Alborz Emergency Department beside the medical and hospital management staff until the end of the transfer operation; 12. Preparing the list of the injured people transferred to the medical centers of the province and uploading the data in the information system of the deputy director of 
treatment and the EOC of the Ministry, simultaneous with the transfer of the injured people; 13. Initiating the third phase of the operation on the following day, November 14, 2017, and re-dispatch of 2 ambulance buses to the west emergency zone of Tehran to carry out other injured people. The dispatch of two ambulance teams consisted of two ambulances and 4 emergency technicians to quake-stricken areas of the west of the country in response to the request of the EOC of the country emergency from November 17, 2017.

\section{Results}

Data analysis is critical for checking the accuracy and reliability of the assumptions of any research. Today, in most research studies that rely on information collected from the subject under investigation, data analysis is considered the most crucial part of the study. Raw data are analyzed and processed using statistical software, and then the obtained information is made available to the users. To analyze the collected data, descriptive and inferential statistics are used. In this research, all statistical analyses were performed in SPSS V. 20.

According to the obtained results, 25-27 years old and 80 years old group were the highest number of wounded people who received services (Figure 1). According to the results, the number of male injured people who received health services was more than female injured people (38 men Vs. 37 women) (Table 2). Shahid Madani Hospital with the admission of $54(72 \%)$ injured was at the top of the receiving and admitting the injured individuals (Table 3). According to the analysis, multiple trauma with the high percentage (24\%), followed by leg trauma $(9 \%)$ and waist trauma, and broken hand (6.8\%) had the highest rates of trauma among the injured people (Table 4).
According to Figure 2, the total of 75 transferred injured people, $39(52 \%)$ of the cases underwent surgical procedures. Twenty-seven (11\%) people took a CT scan. Eight (3\%) underwent MRI. Fourteen (18\%) underwent sonography. Thirty-three (44\%) received orthopedic services. Three (4\%) received neurological services. Five $(6.7 \%)$ received general services. One $(1.3 \%)$ was hospitalized in the ICU, and one person underwent dialysis; eventually, $74(98.7 \%)$ were treated and discharged. There were no deaths among the injured.

According to Table 5 and Figure 3 one case was sent to a hospital in Tehran Province, and 7 (9\%) of the inquired were provided with temporary residents. There was one case of amputation and one case of re-hospitalization. A total of $4(5 \%)$ left the hospital.

\section{Discussion}

According to the Table 1 and obtained data, the age range of 25-27 years, followed by 80 years comprised the highest number of injured people who received medical services. Based on the results, the number of male injured people who received healthcare services were more than females ( 38 men to 37 women). Madani Hospital had the highest number of injured people admission (54 people; 72\%), followed by Alborz Hospital, and Imam Ali Center.

Based on the analysis, multiple trauma had the highest percentage (24\%), followed by leg trauma (9\%), then waist trauma and broken hand (6.8\%) among the injured people. This statistics calls for planning and taking measures in therapeutic centers to develop and implement emergency trauma teams. Of 75 transferred injured people, 39 (52\%) cases underwent surgeries. One case was transferred to a hospital in Tehran Province. Seven (9\%)

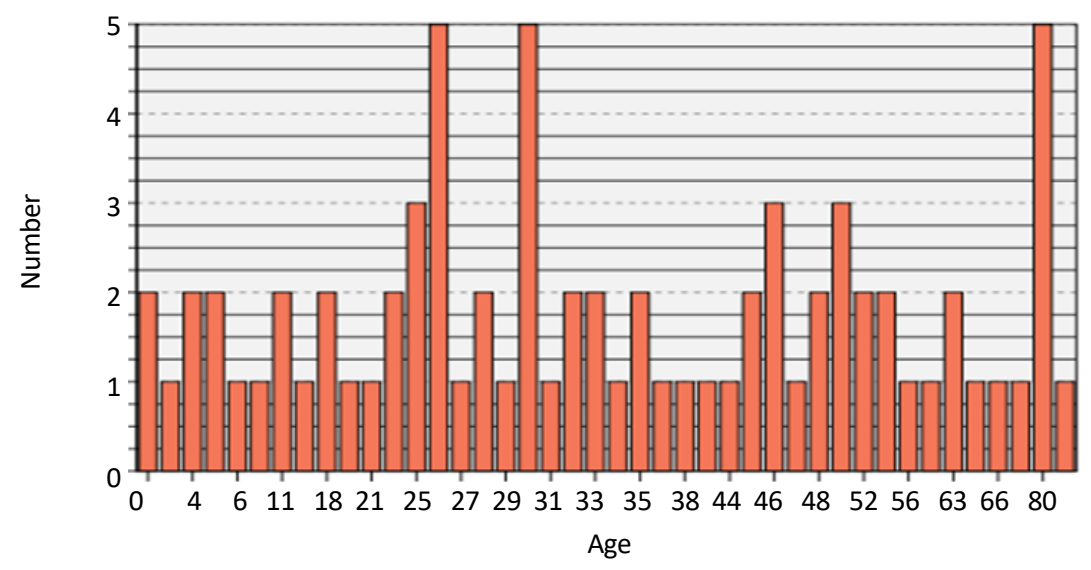

Figure 1. The injured people's age transferred to Alborz Province 
Table 1. Frequency distribution of the number of injured people with respect to age and percentage

\begin{tabular}{|c|c|c|c|c|}
\hline Age, $y$ & No. & $\%$ & Valid \% & Cumulative \% \\
\hline 0.00 & 2 & 0.8 & 2.7 & 2.7 \\
\hline 2.00 & 1 & 0.4 & 1.3 & 4.0 \\
\hline 4.00 & 2 & 0.8 & 2.7 & 6.7 \\
\hline 5.00 & 2 & 0.8 & 2.7 & 9.3 \\
\hline 6.00 & 1 & 0.4 & 1.3 & 10.7 \\
\hline 8.00 & 1 & 0.4 & 1.3 & 12.0 \\
\hline 11.00 & 2 & 0.8 & 2.7 & 14.7 \\
\hline 14.00 & 1 & 0.4 & 1.3 & 16.0 \\
\hline 18.00 & 2 & 0.8 & 2.7 & 18.7 \\
\hline 20.00 & 1 & 0.4 & 1.3 & 20.0 \\
\hline 21.00 & 1 & 0.4 & 1.3 & 21.3 \\
\hline 22.00 & 2 & 0.8 & 2.7 & 24.0 \\
\hline 25.00 & 3 & 1.2 & 4.0 & 28.0 \\
\hline 26.00 & 5 & 2.0 & 6.7 & 34.7 \\
\hline 27.00 & 1 & 0.4 & 1.3 & 36.0 \\
\hline 28.00 & 2 & 0.8 & 2.7 & 38.7 \\
\hline 29.00 & 1 & 0.4 & 1.3 & 40.0 \\
\hline 30.00 & 5 & 2.0 & 6.7 & 46.7 \\
\hline 31.00 & 1 & 0.4 & 1.3 & 48.0 \\
\hline 32.00 & 2 & 0.8 & 2.7 & 50.7 \\
\hline 33.00 & 2 & 0.8 & 2.7 & 53.3 \\
\hline 34.00 & 1 & 0.4 & 1.3 & 54.7 \\
\hline 35.00 & 2 & 0.8 & 2.7 & 57.3 \\
\hline 37.00 & 1 & 0.4 & 1.3 & 58.7 \\
\hline 38.00 & 1 & 0.4 & 1.3 & 60.0 \\
\hline 43.00 & 1 & 0.4 & 1.3 & 61.3 \\
\hline 44.00 & 1 & 0.4 & 1.3 & 62.7 \\
\hline 45.00 & 2 & 0.8 & 2.7 & 65.3 \\
\hline 46.00 & 3 & 1.2 & 4.0 & 69.3 \\
\hline 47.00 & 1 & 0.4 & 1.3 & 70.7 \\
\hline
\end{tabular}




\begin{tabular}{|c|c|c|c|c|c|c|}
\hline Age, y & No. & & $\%$ & & Valid \% & Cumulative \% \\
\hline 48.00 & 2 & & 0.8 & & 2.7 & 73.3 \\
\hline 50.00 & 3 & & 1.2 & & 4.0 & 77.3 \\
\hline 52.00 & 2 & & 0.8 & & 2.7 & 80.0 \\
\hline 55.00 & 2 & & 0.8 & & 2.7 & 82.7 \\
\hline 56.00 & 1 & & 0.4 & & 1.3 & 84.0 \\
\hline 62.00 & 1 & & 0.4 & & 1.3 & 85.3 \\
\hline 63.00 & 2 & & 0.8 & & 2.7 & 88.0 \\
\hline 65.00 & 1 & & 0.4 & & 1.3 & 89.3 \\
\hline 66.00 & 1 & & 0.4 & & 1.3 & 90.7 \\
\hline 70.00 & 1 & & 0.4 & & 1.3 & 92.0 \\
\hline 80.00 & 5 & & 2.0 & & 6.7 & 98.7 \\
\hline 86.00 & 1 & & 0.4 & & 1.3 & 100.0 \\
\hline Total & 75 & & 30.7 & & 100.0 & \\
\hline \multicolumn{2}{|c|}{ Age, year } & Frequency & & $\%$ & Valid \% & Cumulative \% \\
\hline Missing & System & 169 & & 69.3 & & \\
\hline Total & & 244 & & 100.0 & & \\
\hline
\end{tabular}
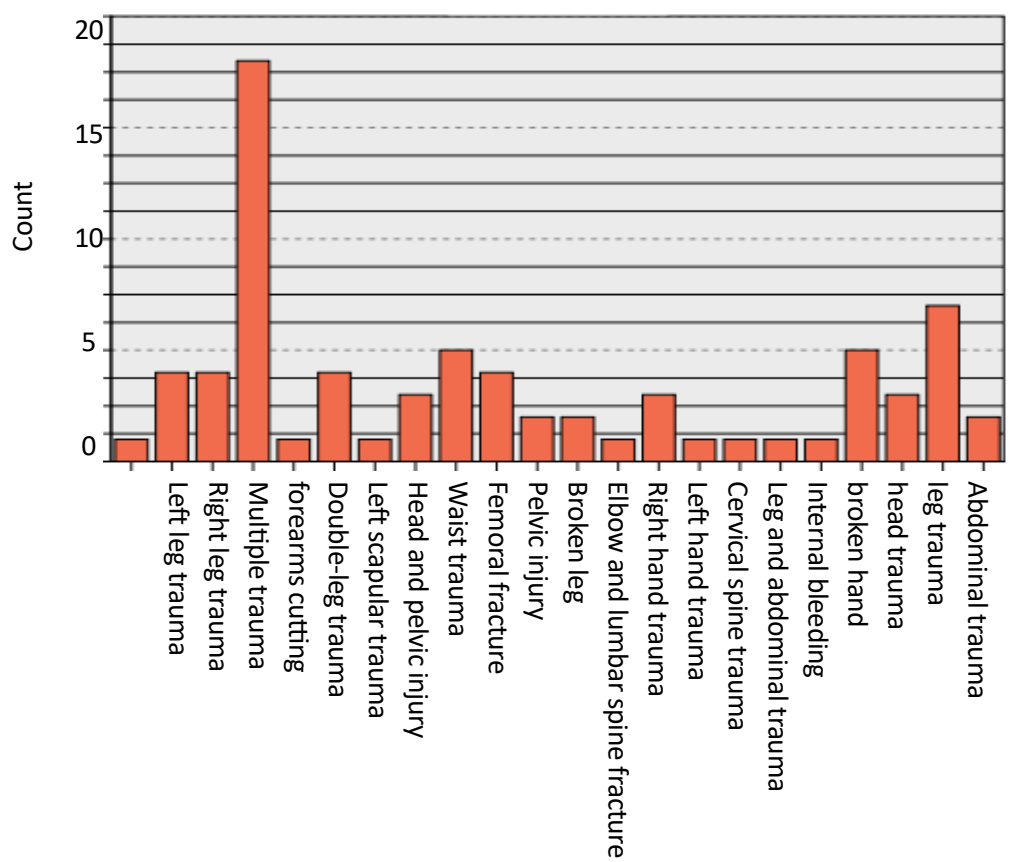

Type of injury

Figure 2. Frequency and percentage of injured people transferred to Alborz Province 
Table 2. Distribution of the injured people by gender and percentage

\begin{tabular}{|c|c|c|c|c|c|}
\hline \multicolumn{2}{|c|}{ Variable } & No. & $\%$ & Valid \% & Cumulative \% \\
\hline & Female & 37 & 15.2 & 49.3 & 49.3 \\
\hline \multirow[t]{2}{*}{ Gender } & Male & 38 & 15.6 & 50.7 & 100.0 \\
\hline & Total & 75 & 30.7 & 100.0 & \\
\hline \multirow[t]{2}{*}{ Missing } & System & 169 & 69.3 & & \\
\hline & & 244 & 100.0 & & \\
\hline
\end{tabular}

Table 3. The admission number of each hospital based on the number of transferred patients

\begin{tabular}{|c|c|c|c|c|c|}
\hline & Variable & No. & $\%$ & Valid \% & Cumulative \% \\
\hline \multirow{4}{*}{ Valid } & Shahid Madani Hospital & 54 & 22.1 & 72.0 & 72.0 \\
\hline & Imam Ali Hospital & 7 & 2.9 & 9.3 & 81.3 \\
\hline & Alborz Hospital & 14 & 5.7 & 18.7 & 100.0 \\
\hline & Total & 75 & 30.7 & 100.0 & \\
\hline \multirow[t]{2}{*}{ Missing } & System & 169 & 69.3 & & \\
\hline & Total & 244 & 100.0 & & \\
\hline
\end{tabular}

Table 4. Frequency and percentage of injuries of the transferred people to Alborz Province

\begin{tabular}{cccccc}
\hline & \multicolumn{2}{c}{ Injury } & & & \\
\hline Variable & No. & $\%$ & Valid \% & Cumulative \% \\
\hline 0.00 & 1 & 0.4 & 1.4 & 1.4 \\
\hline Left leg trauma & 4 & 1.6 & 5.4 & 6.8 \\
\hline Right leg trauma & 4 & 1.6 & 5.4 & 12.2 \\
\hline Multiple trauma & 18 & 7.4 & 24.3 & 36.5 \\
\hline Cutting of forearms & 1 & 0.4 & 1.4 & 37.8 \\
\hline Double-leg trauma & 4 & 1.6 & 5.4 & 43.2 \\
\hline Left scapular trauma & 1 & 0.4 & 1.4 & 44.6 \\
\hline Head and pelvis trauma & 3 & 1.2 & 4.1 & 48.6 \\
\hline Waist trauma & 5 & 2.0 & 6.8 & 55.4 \\
\hline Femoral fracture & 4 & 1.6 & 5.4 & 60.8 \\
\hline Pelvic trauma & 2 & 0.8 & 2.7 & 63.5 \\
\hline Broken leg & 2 & 0.8 & 2.7 & 66.2 \\
\hline
\end{tabular}




\begin{tabular}{|c|c|c|c|c|}
\hline \multicolumn{5}{|c|}{ Injury } \\
\hline Variable & No. & $\%$ & Valid \% & Cumulative \% \\
\hline Elbow and lumbar spine fracture & 1 & 0.4 & 1.4 & 67.6 \\
\hline Right hand trauma & 3 & 1.2 & 4.1 & 71.6 \\
\hline Left hand trauma & 1 & 0.4 & 1.4 & 73.0 \\
\hline Cervical spine trauma & 1 & 0.4 & 1.4 & 74.3 \\
\hline Leg and abdomen trauma & 1 & 0.4 & 1.4 & 75.7 \\
\hline Internal bleeding & 1 & 0.4 & 1.4 & 77.0 \\
\hline Broken hand & 5 & 2.0 & 6.8 & 83.8 \\
\hline Head trauma & 3 & 1.2 & 4.1 & 87.8 \\
\hline Leg trauma & 7 & 2.9 & 9.5 & 97.3 \\
\hline Abdominal trauma & 2 & 0.8 & 2.7 & 100.0 \\
\hline Total & 74 & 30.3 & 100.0 & \\
\hline Variable & $\%$ & Valid \% & Cumulative \% & Cumulative Percent \\
\hline Missing & 170 & 69.7 & & \\
\hline Total & 244 & 100.0 & & \\
\hline
\end{tabular}

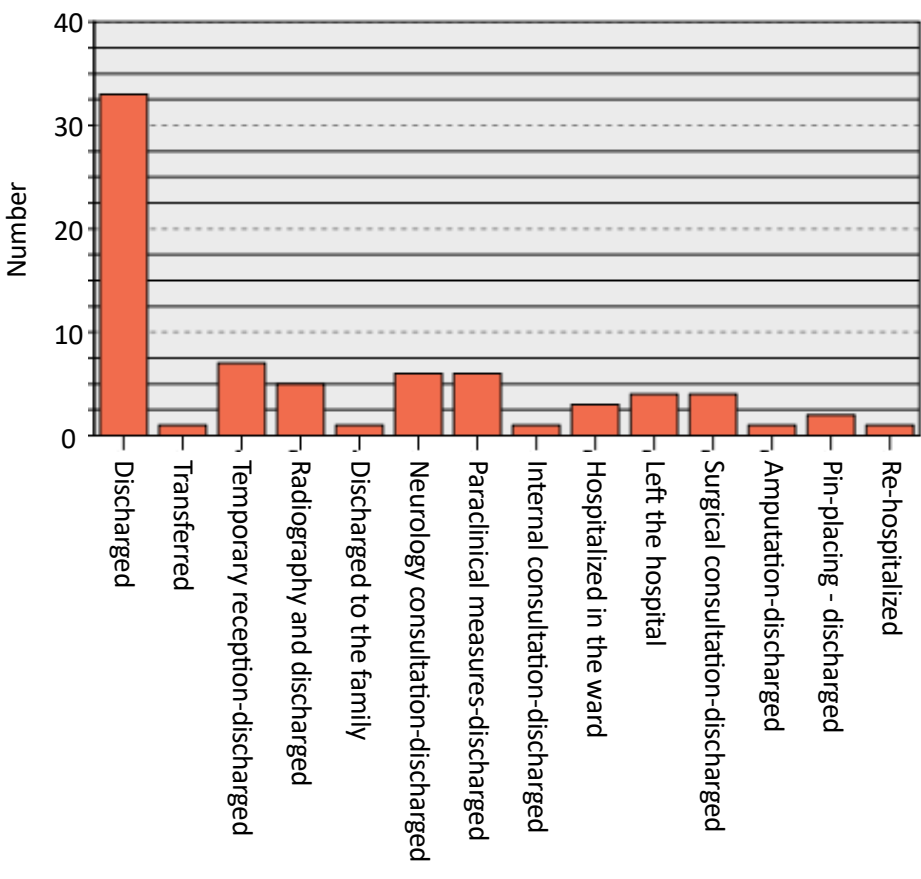

Taken measures

Figure 3. The measures taken at the treatment centers 
Table 5. All services provided to the injured

\begin{tabular}{|c|c|c|c|c|c|}
\hline Variable & No. & $\%$ & Valid \% & Cumulative \% & Cumulative Percent \\
\hline & Discharged & 33 & 13.5 & 44.0 & 44.0 \\
\hline & Transferred & 1 & 0.4 & 1.3 & 45.3 \\
\hline & Temporary reception-discharged & 7 & 2.9 & 9.3 & 54.7 \\
\hline & Took graphy, discharged & 5 & 2.0 & 6.7 & 61.3 \\
\hline & Discharged to the family & 1 & 0.4 & 1.3 & 62.7 \\
\hline & Neurology consultation-discharged & 6 & 2.5 & 8.0 & 70.7 \\
\hline & Paraclinical measures-discharged & 6 & 2.5 & 8.0 & 78.7 \\
\hline \multirow[t]{8}{*}{ Outcome } & Internal consultation-discharged & 1 & 0.4 & 1.3 & 80.0 \\
\hline & Hospitalized in the ward & 3 & 1.2 & 4.0 & 84.0 \\
\hline & Left the hospital & 4 & 1.6 & 5.3 & 89.3 \\
\hline & Surgical consultation-discharged & 4 & 1.6 & 5.3 & 94.7 \\
\hline & Amputation-discharged & 1 & 0.4 & 1.3 & 96.0 \\
\hline & Pin-placing - discharged & 2 & 0.8 & 2.7 & 98.7 \\
\hline & Re-hospitalized & 1 & 0.4 & 1.3 & 100.0 \\
\hline & Total & 75 & 30.7 & 100.0 & \\
\hline \multirow[t]{2}{*}{ Missing } & System & 169 & 69.3 & & \\
\hline & Total & 244 & 100.0 & & \\
\hline
\end{tabular}

cases were provided with temporary residence. One amputation was done, and one re-hospitalization was performed. Four (5\%) patients left the hospital.

\section{Conclusion}

Regarding the services provided, it can be acknowledged that the Crisis Operations Command Headquarters of Alborz Medical Sciences University showed an excellent performance regarding the risk management of accidents and disasters in the Kermanshah's November earthquake, given the recent establishment this headquarters and the type and amount of the services provided to the injured.

Planning the operations, triage at the airport, the transfer of the injured, coordination with the hospitals, and announcing yellow status to all medical centers and using the full capacity of the Medical Sciences University, the assignment of beds and the increasing capacity of health centers, making relationships with organizations, centers, and hospitals affiliated to Alborz University of Medical Sciences have been among the critical activities of the Crisis Operation Command Headquarters.

Admission and management of 75 injured people with different ages and genders and providing appropriate and efficient healthcare services and follow-up after discharge and the settlement of injured and their companions were among such services of the center. These measures reflect the efficient and timely response of the Crisis Operations Command Headquarters of Alborz University of Medical Sciences.

\section{Ethical Considerations}

\section{Compliance with ethical guidelines}

All contents of this article were conducted in accordance with The Helsinki Declaration principles, and all data werekept confidential and not used in othercenters. 


\section{Funding}

This article was an organizational response template and included all actions of the Alborz Medical School Operations Center.

\section{Authors' contributions}

Conceptualization, neda mohammadi; methodology: all author; Investigation: Neda Mohammadi and Mehrdad Babie; Writing-original draft: Farzaneh Ahmadzadeh; Writing-review \& editing: Farzaneh Ahmadzade; Funding acquisition: Dr Mehrdad Babie; Resources: All author; Super conceptualization: Farzaneh ahmadzadeh.

\section{Conflict of interest}

The authors declared no conflict of interest.

Acknowledgments

All staff of the Alborz Medical University Operations Command, Headquarters, staff and sympathetic staff of the Alborz University of Medical Sciences Hospitals

\section{References}

[1] Cox E, Briggs S. Disaster nursing: New frontiers for critical care. Critical Care Nurse. 2004; 24 (3):16-22. [PMID]

[2] Joukar F, Salami Kohan K, Reza Masouleh Sh, Rashidian N. [Nurses educational situation related to facing the disasters (Persian)]. Journal of Guilan University of Medical Sciences. 2007; 9(1):32-37.

[3] Halpern JS, Chaffee MW. Disaster management and response. Nursing Clinics of North America. 2005; 40(3):xiii-xv. [DOI:10.1016/j.cnur.2005.04.001]

[4] Fortuno L. A nurse's story of hurricane Charley. The Florida Nurse. 2004; 52(3):12. [PMID]

[5] Ghanbari V, Maddah SS, Khankeh HR, Karimloo M, Ardalan A. [The effect of a disaster nursing education program on nurses' preparedness for responding to probable natural disasters (Persian)]. 2011; 24(73):72-80.

[6] Lutz LD, Lindell MK. Incident command system as a response model within emergency operation centers during hurricane Rita. Journal of Contingencies and Crisis Management. 2008; 16(3):122-34. [DOI:10.1111/j.1468-5973.2008.00541]

[7] Ryan M. Planning in the emergency operations center. Technological Forecasting and Social Change. 2013; 80(9):1725-31. [DOI:10.1016/j.techfore.2013.01.006]

[8] Militello LG, Patterson ES, Bowman L, Wears R. Information flow during crisis management: Challenges to coordination in the emergency operations center. Cognition, Technology
\& Work. Springer Science and Business Media LLC. 2006; 9(1):25-31. [DOI:10.1007/s10111-006-0059-3]

[9] Mignone AT Jr, Davidson R. Public health response actions and the use of emergency operations centers. Prehospital and Disaster Medicine. 2003; 18(3):217-9. [DOI:10.1017/ S1049023X00001084] [PMID]

[10] Barzouei B, Khorasani Zadeh M, Rahimi AA. [Improvement of urban crisis management through synergy of certain cities (Case Study of Qom City) (Persian)]. Paper presented at: $6^{\text {th }}$ International Conference on Crisis Management. 17-18 March 2015; Tehran, Iran.

[11] Khanka HR, Rakhshandeh M, Ahmadi F. [Health services management in natural disasters: A qualitative study (Persian)]. Paper presented at: National Congress on Crisis Management Promotion in Disaster-Related Accidents. 20 August 2006; Zanjan, Iran. 